\title{
Analysis of the Effect of Welding on SPSW Stress
}

\author{
LAN Tao ${ }^{1,2, a^{*}}$, WANG Yu ${ }^{2, b}$, GAO Ruixiang ${ }^{3, c}$ and HU Weizhong ${ }^{1, d}$ \\ ${ }^{1} \mathrm{Xi}$ ' an University of Architecture and Technology, China \\ ${ }^{2}$ CSIC Architecture Design and Research Institute Co. Ltd, China \\ ${ }^{3}$ Taiyuan University of Science and Technology, China \\ aqd_lantao@163.com¹, bwangyu_7307@126.com, ${ }^{\text {c9 }}$ 21302083@qq.com, ${ }^{d}$ hwz_2016@163.com
}

\begin{abstract}
Welding is a major connection mode of SPSW (Steel Plate Shear Wall). However, the residual stress and deformation have great influence on the SPSW bearing capacity. A sound welding sequence and a welding technology are required so as to minimize the negative effect on SPSW stress. Therefore, in this paper, Exquisite FEM is selected as the way to analyze the full welding process of SPSW. Accordingly, the basic principles of SPSW welding are discussed in this paper.
\end{abstract}

\section{Introduction}

The bolted connection of SPSW makes the construction more difficult [1] and makes noise [2] at same time, so the welding connection is introduced. This paper states that the residual stress and deformation caused by welding are main factors of SPSW stress, based on an analysis of the welding connection in the SPSW construction. Therefore, the author established the Exquisite FEM of SPSW for the whole welding process by using the finite element numerical simulation means and puts forward the basic principles of SPSW welding. This paper provides the guidance for the builders.

\section{Numerical Simulating Analysis}

The frames impose a restriction [3] to SPSW because the stiffness of frames is greater than that of steel plates. Hence, the welding is the common connection method between SPSW and its surrounding frames. Meanwhile, the residual stress and deformation of main structure occur in the SPSW welding, especially in the thick slabs. The welding sequence and technology which could minimize the stress effect of residual stress and deformation on the structure become a problem of concern to the designers and builders. [4] To this end, taking a piece of SPSW in Beijing Wealth Building Phase 3 as the model test object, this paper makes an analysis on the whole welding process of SPSW by using the finite element

\footnotetext{
*Corresponding author:qd_lantao@163.com
} 
numerical simulation means, and then explains the basic welding principles of common SPSW accordingly.

Numerical Simulating Analysis Model. Beijing Wealth Building Phase 3 lies in CBD of the East Third Ring Road with the area of $175,900 \mathrm{~m}^{2}$ and the height of $262 \mathrm{~m}$. The core tube of this building is composite steel plate wall. One unit SPSW in this building is selected for the welding model test. In this test, the SPSW is embedded in the rigid frames of core tube. In order to prevent the reduction of ultimate bearing capacity from axial compression, it is assumed that we connect the upper edge of SPSW with the frame girder by welding method and the other four edges of SPSW have the reserved welding seams with the three sides of the beam column. Then, the reserved welding seams were jointing. The sizes of the welding parts are shown in Fig.1.

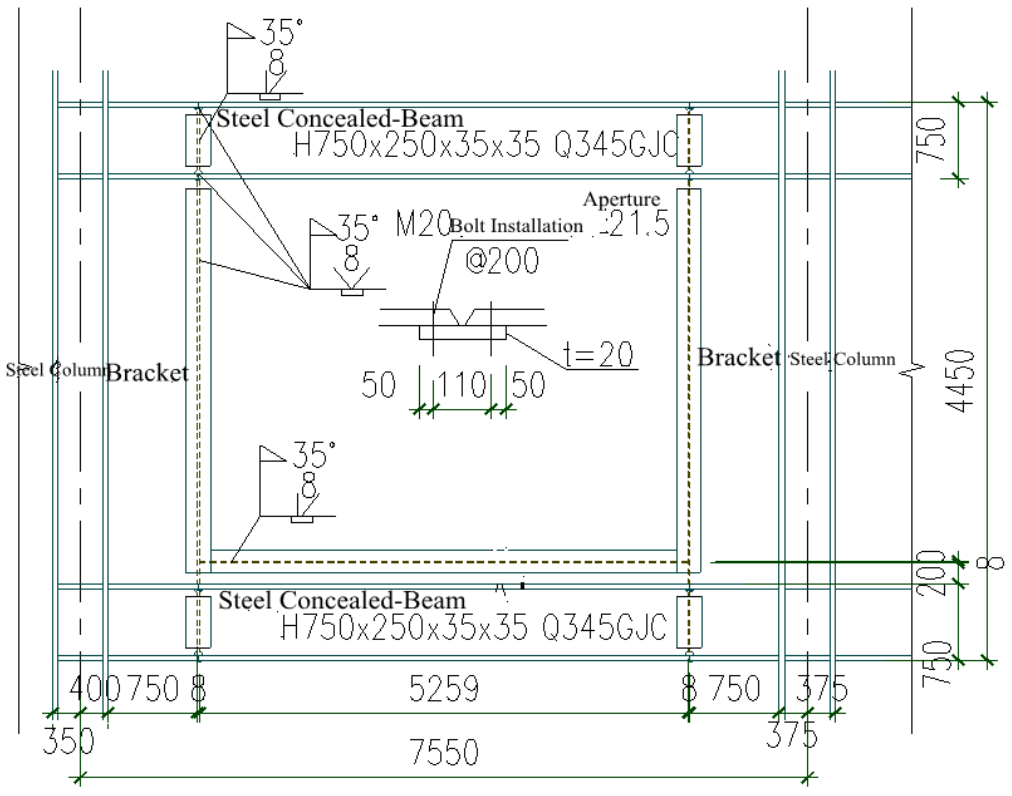

Fig.1.The SPSW welding simulation area

The aim of finite element simulation of welding is: 1) to model the specific values of residual stress and deformation of SPSW caused by welding thick steel plates; 2) to acquire the best welting methods of thick SPSW through the analysis of welding sequence; 3) to demonstrate the reasonability of the calculation model through analyzing the stiffness of the different surrounding components of SPSW.

There are various sequences in welding the above three (right edge, left edge and lower edge) welding seams. The welding sequence of thick SPSW could be identified in accordance with the principle of the component with greater restraining stiffness first. As shown in Fig.2, the sequence is (1)vertical welding seam $\rightarrow$ (2)vertical welding seam $\rightarrow$ (3) horizontal welding seam.

Therefore, the discontinuous welding is adopted in the actual construction in order to avoid the hog deformation caused by longitudinal shrinkage of welding seam and the steel plates corrosion caused by incompact welding. The welding seam sequence of (1)and(2) is that : we should conduct the discontinuous welding from up to down by the welding principle of $500 \mathrm{~mm}$ and $500 \mathrm{~mm}$; the discontinuous welding again occurs in the non-welding area. The horizontal welding seam could be divided the welding seams with equal length (within 
$500 \mathrm{~mm} \sim 1000 \mathrm{~mm})$. Then, many welders conduct the back-step welding in one direction. In the Exquisite FEM of SPSW, the welding seam units are activated by this welding sequence.

In the FEM of SPSW, Beam188 unit is chosen as the beam and column and the Shell181unit is selected as the SPSW, Solid5 is selected as the welding seam. Besides, welded convective boundary, displacement boundary and rigid zone are all considered as the boundary condition in this model test. The Exquisite FEM is shown in Fig.2.

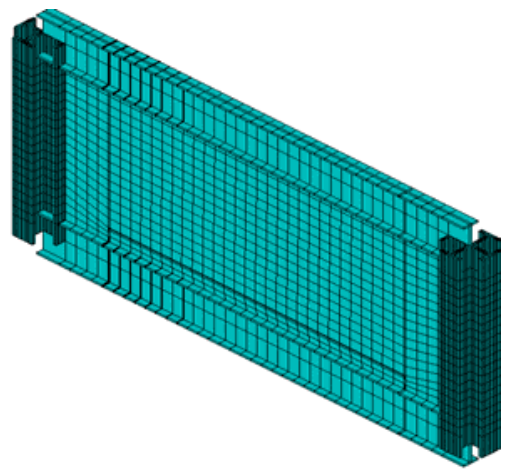

Fig.2.The SPSW finite elements model

Analysis of Test Results. Deformation, residual stress and temperature field occur after welding, which are respectively shown in Fig.3and Fig.4.

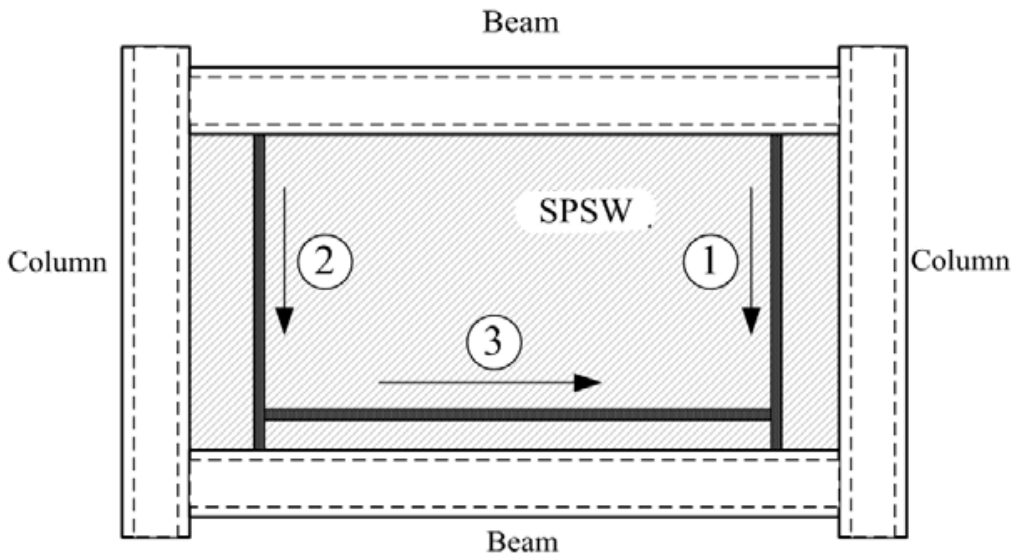

Fig.3.The welding sequence of typical SPSW 


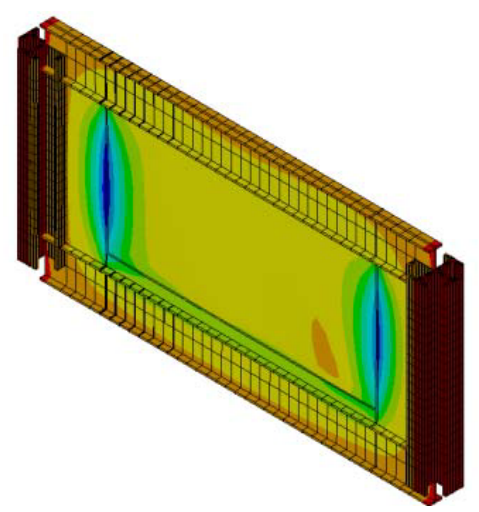

(a)The out-of-plane deformation of SPSW

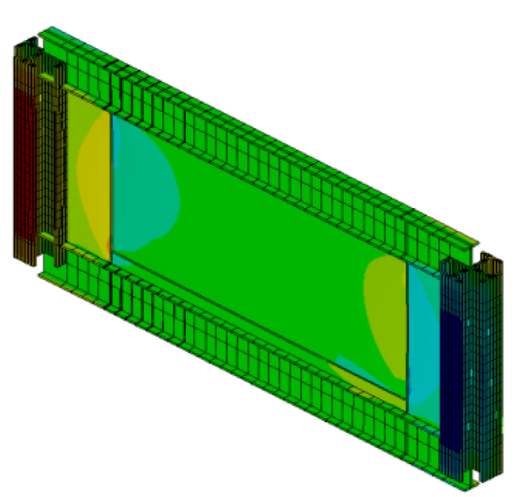

(b)The in-plane deformation of SPSW

Fig.4.The SPSW deformation after welding

As Fig.5 shows, welding sequence of both vertical welding seams and one horizontal welding seam causes that cooling contraction occurs successively. After plates are in cool, the buckling deformation clearly occurs in the welding joint of SPSW with less stiffness. The Mises stress is little in the most part of SPSW (except for welding seam), with about 50MPa. However, the residual stress in the welding seams exceeds the steel yield strength due to the reinforcement of yield stress. Especially, under the complex stress condition, the residual stress is too much in the junction between the vertical welding seam and the horizontal welding seam, leading to deformation of SPSW (See Fig.5 (b)). The results show that welding cannot occur in the welding joints in the actual situation and the horizontal welding seam should be cut off.

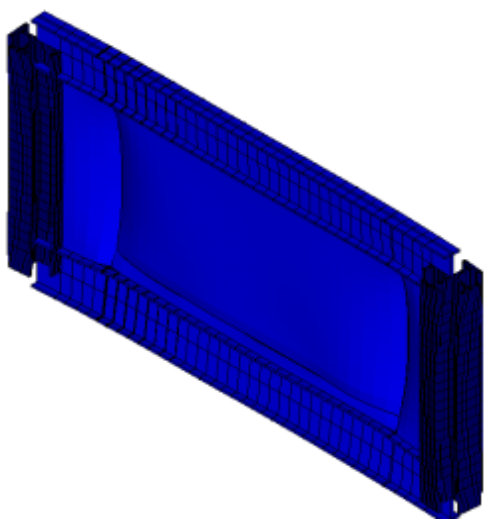

(a)The Mises stress after cooling

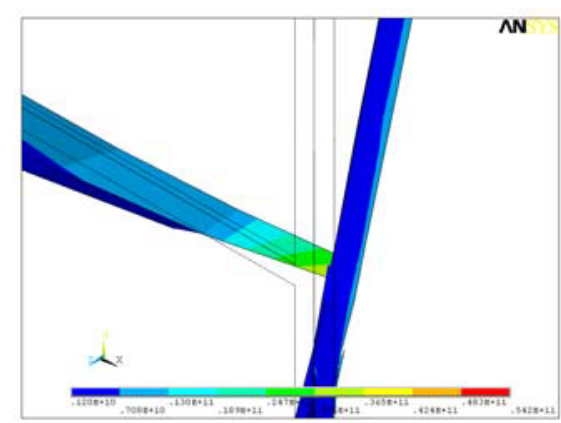

(b) The diagram of stress field after cooling

Fig.5.SPSW stress field after welding

In order to explore the restraints stiffness of the frame which is imposed on the SPSW in the welding process, counter force of SPSW left margin in two kinds of boundary conditions is selected in the finite element model, including that: 1) with the displacement of four corners of restrictive frames, shrinkage force in SPSW is transformed to the end reaction of 
frame corners; 2) the restriction is directly imposed on the four sides of SPSW. The Table1 shows the values of axial force $\mathrm{N}$ and shear force $\mathrm{V}$ of left margin of SPSW.

Table 1 The values of axial force $\mathrm{N}$ and shear force $\mathrm{V}$ of left margin of SPSW.

\begin{tabular}{c|c|c|c}
\hline \multicolumn{2}{c|}{ Constrain type } & N $(\mathrm{N})$ & $\mathrm{V}(\mathrm{N})$ \\
\hline (1) & Restrictive frame & 12755 & 22537 \\
(2) & Restrictive SPSW & 20190 & 30674 \\
\hline
\end{tabular}

The figures in Table1 show that: support reaction force in restrictive SPSW is higher than that in restrictive frame; the axial force in restrictive SPSW is 1.58 times of that in restrictive frame; shear force in restrictive SPSW is 1.36 times of that in restrictive frame. This is because the constraining force imposed by the framework beam-column in restrictive frame is less than that in restrictive SPSW. Besides, in the actual structure, the shrinkage action of SPSW is collaboratively effected by the framework beam-column, so the condition of restrictive frame is more feasible.

All the following test results are obtained from the above model test. (1)The residual stress and deformation caused by welding occur in the steel structure. In the actual measurement, the out-of-plane deformation of SPSW is about $30.0 \mathrm{~mm}$ which is matched with the result obtained from the finite elements calculation. (2)The rational welding sequence and methods could effectively reduce the residual stress in the structure. (3)The proper boundary condition of FEM has a great impact on the calculation results. For this model test, the shrinking of SPSW is not a separate action but a coordinated work under the restriction of surrounding components. Therefore, the reasonable boundary conditions could ensure the accuracy of FEM.

Recommendations on Welding Sequence. In order to minimize the residual stress and deformation, the components with greater stiffness should be welded at first, and then the components with little stiffness are not far behind.

A philosophy of Strong Column Weak Beam is adopted in the structural design, including the structural design of SPSW. SPSW in the elastic stage mainly depends on the lateral stiffness supported by the beams and columns; SPSW at phase of elastic-plasticity consumes energy in the earth quake by the tension field caused by the interaction of steel plates around beams and columns and anchorage. Thus, the stiffness of columns in SPSW is much greater than that of common frame columns. As a result, the best welding sequence is selected in the construction site as follows: the vertical welding seam is first, which is followed by horizontal seam.

As for SPSW with different thickness, different welding methods are adopted even for the welding seams in the same direction. In the vertical direction, the thick plates welding seams and mid-thick plates welding seams require welding by layers and lane, especially for one-side and double-side groove welding seams, so discontinuous welding is used to decrease the influence of residual stress and deformation. However, in order to prevent the welding defects, hierarchical welding methods could be adopted in the thin slab welding seams due to the small depth and width of welding seams (butt weld).

Horizontal welding seam in the lower place of SPSW is ranked in the last place of welding sequence. With the considerable constraints from surrounding components, the segmental back welding is adopted to join the horizontal welding seams to minimize the residual stress and deformation of welding. The welding seam connection is adopted in the typical SPSW. (See Fig.6) 


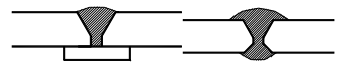

(a)Thick slab welding seam

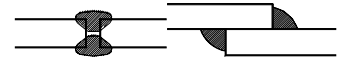

(b)Thin slab welding seams

Fig.6.The SPSW welding seam forms

Additionally, in the welding of SPSW, in order to prevent the enormous deformation, joint welding is not required in all welding seams. That is to say, vertical welding seams should be welded at first; however, we should cut off the joint between horizontal welding seams and the vertical welding seams in the welding process.

\section{Conclusion}

Welding is the major connection way of SPSW. However, the residual stress and welding deformation have an influence on the SPSW bearing capacity. A reasonable welding sequence and a welding technology are required so as to minimize the negative effect on SPSW stress. Therefore, in this paper, Exquisite FEM is selected as the way to analyze the full welding process of SPSW. The basic principles of SPSW welding are discussed accordingly, which is conductive for the designers and builders.

\section{References}

1. Lan Tao, Guo Yanlin, Hao Jiping, Influence of welding stress on the ultimate bearing capacity of steel plane shearing wall(SPSW)with opening, J. Construction Technology, 40 (2011).

2. Zhou Ming, Studies on Design Method of Unstiffened or Buckling-Restrained Steel Plate Shear Wall Structures, D. Tsinghua University, 2009.

3. Lan Tao, Study on the Construction Design Theory and Methods of Steel Plate Shear Wall with Openings, D. Xi' an University of Architecture \& Technology, 2011.

4. Lan Tao, Guo Yanlin, Hao Jiping, Stress Analysis of Edge Members to SPSW with Openings, J. Industrial Construction, 41(2011). 